\title{
ONLINE LEARNING IN EDUCATION SECTOR REVEALING THE BENEFITS AND CHALLENGES
}

\author{
Prof. N. Venkata Rao \\ Department of Education, Andhra University, Andhra Pradesh, India- 530003 \\ P. Divakara Rao \\ Department of Education, Andhra University, Andhra Pradesh, India- 530003
}

Article DOI: https://doi.org/10.36713/epra5218

\begin{abstract}
-
COVID-19 pandemic has led to secure disruptions in normal life, including closure of schools. It has impacted over 240 million children of the country who are enrolled in schools. Extended school closures may cause loss of learning. Online courses have the potential to open the pathways for more opportunities for students in "small, rural, or low socioeconomic school districts". Online courses offer an excellent way for students to expand their educational opportunities and keep on competitive in the ever challenging realm of education. Students embarking on the path of higher education through online coursework need to be self-motivated, independent, and responsible learners. Understanding one's learning style and skills will allow students to more accurately determine if online learning is suitable for them. Instructors and course designers will also benefit from understanding the aspects of a course that increase students' understanding and participation. Communication in terms of supportive comments, constructive criticism, and prompt feedback from instructors to students is a key component of online courses. There are a number of drawbacks and potential issues that students may face while participating in an online course.
\end{abstract}

\section{INTRODUCTION}

COVID-19 pandemic has led to secure disruptions in normal life, including closure of schools. It has impacted over 240 million children of the country who are enrolled in schools. Extended school closures may cause loss of learning. To mitigate the impact of the pandemic, schools will not only have to remodel and reimagine the way teaching and learning have happened so far, but will also need to introduce a suitable method of delivering quality education through a healthy mix of schooling at home and schooling at school.

While digital or online education cannot replace classroom learning, it has some advantages. It allows flexible and personalized learning at the speed of the learner and one can continuously augment and expand content through digital means. The rapid increase in internet penetration and various government initiatives such as Digital India campaign have created a conductive environment for moving towards digital education. This shall be complemented by the recent launch of PM e-vidya by the Ministry of Human Resource Development (MHRD), a national campaign which will unify all efforts related to digital/online/on-air education. This includes, DIKSHA (one nation - one digital platform), TV (one class-one channel), SWAYAM (online MOOCS on various topics), IITPAL (platform for exam preparation), AIR (through community radio and CBSE Shiksha Vani podcast) and study materials for differently abled students developed by NIOS. All these areas of e-learning shall be expanded and developed further in a systematic and unified manner by the MHRD in a phased manner. 


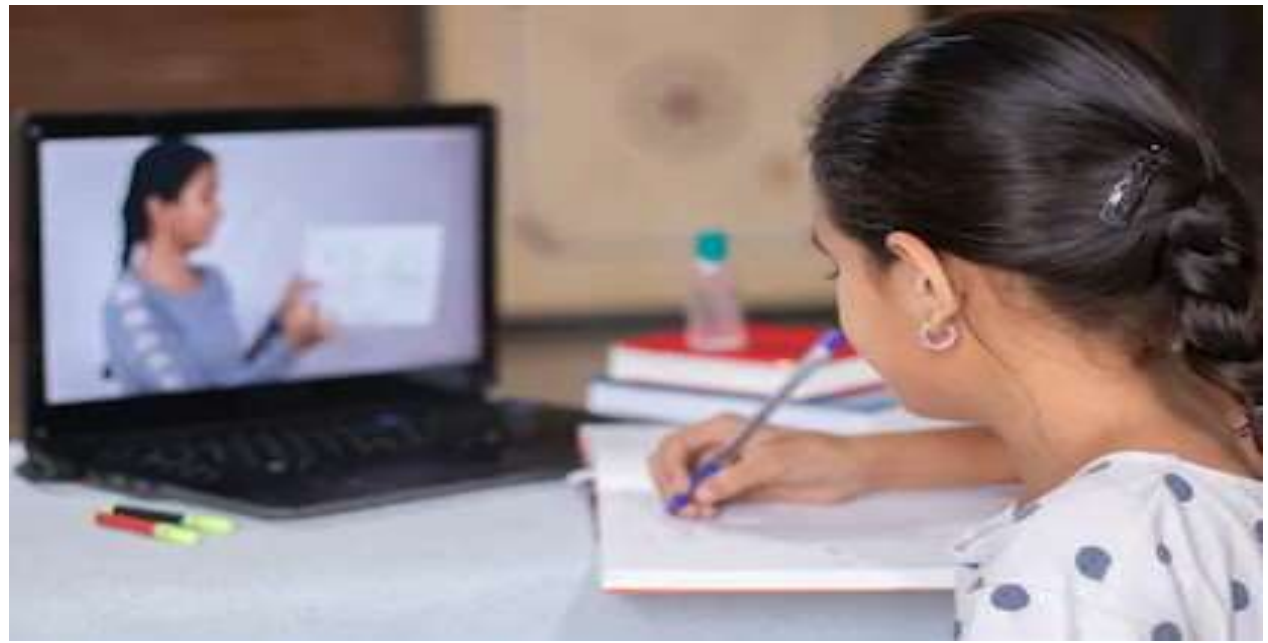

\subsection{Digital Resources}

- Identify and curate digital resources available in national repositories like DIKSHA, e-Pathashala, NROER, NDL e-content portals of different states contents from Open Educational Resources (OERs) repositories like PhET, Khan Academy, MERLOT, Geogebra etc can be identified as per the need of the state and disseminate to all stakeholders.

- The prescribed printed energised textbooks (with QR codes) may be made available to all students to make digital education meaningful and effective.

- The States/ UTs following NCERT syllabus and textbooks may align with the Tv programmes and online education courses like SWAYAM being offered by NCERT. Likewise, States following the same set of textbooks and having a common medium of instruction like in case of Tamil Nadu and Puducherry/ Gujarat and Daman and Diu, need not create separate e-Content. Rather they can share each other's content and system for digital education. Convergence of such efforts may reduce duplication of efforts and parallel structures.

- State specific web portals, TV channels, radio channels etc may be planned (in line with UP, Assam, Punjab, Haryana) to reach all stakeholders.

- A common online platform should be created state wise to enable students, teachers and parents to access or share information including posting queries and questions. Use of IVRS and chat both based solutions may be more useful to address commonly raised concerns/ issues by students, teachers and parents.

\section{TEACHING AND LEARNING}

Teaching and learning are always in demand and when faculty heard about lockdown due to COVID 19, it was a challenge for faculty to look this as an opportunity to go for virtual classrooms, virtual learning and teaching. With the crisis there is a wide adaption of technology in teaching; learning process. The higher educational institutions in Bangalore have opted for online classes. The tools used by faculty during lockdown for teaching and learning through online modes are Zoom, Google Hangouts, Skype meet up, Google classrooms, LMS, ICT, YouTube, etc. Many institutions conducted Faculty development programs online to gear up the positivity among faculty during the crisis. Faculty feel there is no much difference between online and offline sessions as they can share PPT, play videos and use board and marker as regular classrooms. One interesting part, one of the respondents was handling an analytics course for PGDM students and even she can run all the codes online and students were very positive towards the learning and course. And faculty have also done online role-play, group presentations, guest sessions by experts in the field and CEO talk online. This has created a revolution in the higher education institutions and proved the hybrid system of teaching through offline and online mode 


\subsection{Challenges as education providers are rushing to go online}

- Transitioning to online learning at scale is a very difficult and highly complex undertaking for education systems, even in the best of circumstances;

- Moving to online learning at scale raises profound equity concerns;

- Highly motivated learners, especially those with previous experience in online learning, are the most likely to take the most advantage of online learning opportunities;

- When first going online, education systems and parents should expect dips in student achievement in the short term;

- Organizing digital educational content to align with existing curricula can be critical in providing users and teachers with a way to ensure that the learning opportunities provided correspond to broader educational objectives within an education system;

- Making content available on a wide variety of devices and mobile friendly is critical;

- Supporting the use of low bandwidth including offline solutions is key to effective learning;

- Staff teaching online need to be supported;

- Universities need to negotiate with internet vendors to help provide access to online learning for students for free or at a cheaper rate

- Providing supplemental guidance and support on how to use and access remote and online learning content can be critical; and

- Some academic subjects are easier to move online than others.

\subsection{Psychological disturbance Challenges:}

It is normal for faculty and students to undergo stress because of the uncertainty they are facing. Not being able to carry on with a set routine will further add to their anxiety and affect their mental health. Proper psychological support system needs to be established through courses/curriculum and training. Focus should be on maintaining mental well-being in these midcult times.

Need for change The inappropriate exam system, which mostly calls for rote memorization, has failed to test the higher order thinking skills among students. Hence, there is a need for a thorough overhaul. The present one-size-fits-all system only increases the stress on students and parents. Exam procedures often lack of transparency, and students resort to malpractices. The annual/end semester exams have failed to serve the selection needs of the next level of education/career. The existing system calls for urgent reforms. It not only has to be flexible but also fair to all groups. Though many higher education institutions have continuous formative assessments and summative assessments, rarely does the continuous assessment include modes of assessments apart from the written tests. Even the question papers do not test the various cognitive levels as prescribed by the revised Bloom's Taxonomy With so many advantages in going online, this is the best time for Indian higher education institutions to build their digital presence.

\subsection{Benefits Accessibility:}

Universities can reach out to a much wider audience since learners don't need to be physically present in a classroom. This also gives learners a chance to interact with faculty and others from across the country. Universities can think of launching programmes for different sections of population, which can be conducted at times

Convenient for learners; theoretically offering universities a chance to be open $24 \times 7$ and reach out to the largest possible number of learners. With geographical boundaries no longer being a constraint, learners can get access to high-quality education from the best institutions and faculty across the country and possibly even the world. Imagine a scenario where people who hold jobs can work and earn a recognised degree because they are able to learn for a few hours every day after their shift ends. Or someone who is physically unable to travel to a classroom now gets the benefits of a university degree without having to worry about how to get there daily. Affordability: As online degrees scale, the costs associated with delivery will also come down, leading to high-quality education being more affordable. This, in turn, makes it more accessible to a larger section of our population.

Quality: Having no geographical constraints will lead to more competition among universities and force them to invest more in their learning material, motivate faculty to deliver better. 


\subsection{Some of the main advantages of online learning include:}

- Convenience: 24/7 access from any online computer; accommodates busy schedules; no commuting, no searching for parking.

- Enhanced Learning: Research shows increased depth of understanding and retention of course content; more meaningful discussions; emphasis on writing skills, technology skills, and life skills like time management, independence, and self-discipline.

- Leveling of the Playing Field: Students can take more time to think and reflect before communicating; shy students tend to thrive online; anonymity of the online environment.

- Interaction: Increased student-to-teacher and student-to-student interaction and discussion; a more studentcentered learning environment; less passive listening and more active learning; a greater sense of connectedness, synergy.

- Innovative Teaching: Student-centered approaches; increased variety and creativity of learning activities; address different learning styles; changes and improvements can translate to on-ground courses as well.

- Improved Administration: Time to examine student work more thoroughly; ability to document and record online interactions; ability to manage grading online.

- Savings: Accommodate more students; increased student satisfaction $=$ higher retention and fewer repeats.

- Maximize Physical Resources: Lessen demand on limited campus infrastructure; decrease congestion on campus and parking lots.

- Outreach: Give students options; reach new student markets; appeal to current students thus increasing enrollments.

\section{CONCLUSION}

COVID-19 has drastically effected all sectors including education and the world is searching for new strategies to cope with this pandemic and its aftermath. Higher educational institutions are now looking at online teaching learning as a window of hope. But sceptics and cynics have created myths about web learning, which we need to debunk so that we can transition effectively. There is an innate fear in teachers that technology will eventually replace them. Teachers need to be reassured that they cannot be replaced but also need to be told that their role has changed significantly.

Some argue that online teaching subtly favours those who have access to high technologies and turns down the disadvantaged sections of society. There may be some truth here but the larger fact is that online education is meant for all. Online teaching-learning is not as effective as face-to-face mode There are merits and demerits in both ways. But good teachers are always good, whatever the mode.

\section{REFERENCES}

1. Babson Study: Over 7.1 Million Higher Ed Students Learning Online. (n.d.). Retrieved November 23, 2014, from http://www.babson.edu/news-events/babson

2. Bonk, C. J. (2001). Online teaching in an online world. Bloomington, IN: CourseShare.com.news/pages/140115babson-survey-study-of-online-learning.aspx

3. Chandler, P., \& Sweller, J. (1992). The split-attention effect as a factor in the design of instruction. British Journal of Educational Psychology, 62, 233-246.

4. Ryabov, I. (2012). The effect of time online on grades in online sociology courses. Journal of Online Learning and Teaching, 8(1), 13. Retrieved from http://search.proquest.com/ docview/1499783903? accountid=27700

5. Thomson, L. D. (2010). Beyond the Classroom Walls: Teachers' and Students' Perspectives on How Online Learning Can Meet the Needs of Gifted Students. Journal of Advanced Academics, 21(4), 662-712. 